\title{
Automated Residential Demand Response Based on Dynamic Pricing
}

\author{
Benjamin Dupont, Graduate Student Member, IEEE, Jeroen Tant, Graduate Student Member, IEEE, \\ and Ronnie Belmans, Fellow, IEEE
}

\begin{abstract}
Against the background of more renewable energy, limited investment in power generation, ageing distribution and transmission infrastructure, and the electrification of energy, the demand side of the electricity system is gaining attention. Moreover, the increasing ability to automate household appliances allows to involve the demand side more easily. Therefore, this paper examines demand response of residential consumers possessing smart appliances. Starting from day ahead wholesale prices and renewable energy production, different cost reflective Real Time Pricing (RTP) schemes are developed. According to these schemes, white goods are scheduled to the lowest price period taking into account user preferences. These demand modifications bring about new insights in the impact of the introduction of RTP.
\end{abstract}

Index Terms-Demand Response, Dynamic Pricing, Electricity Tariff, Integer Linear Programming, Renewable Energy, Scheduling, Smart Grids.

\section{INTRODUCTION}

$\mathrm{T}$ HE European electricity system is facing tremendous challenges. By 2050, the European Union wants to reduce greenhouse gas emissions by at least $80 \%$ below 1990 levels [1]. One of the ways to overcome this challenge is the integration of Renewable Energy Sources (RES) [2]. As RES are characterised by intermittency, extra resources are needed to match supply and demand at all times. Historically, power markets have focused on the supply side to balance the energy system, while the demand side was considered as fixed. As clean supply side measures become insufficient in the event of booming RES, more active involvement of the demand side is needed. Real Time Pricing (RTP) [3] is one way to engage the demand side. In this dynamic pricing structure consumers receive hourly prices, reflecting the underlying cost of energy. Typically, hourly prices are higher when electricity demand is high as expensive peaking plants are online. This relationship can change in view of a massive introduction of RES, as the reduction of hourly prices induced by a peak of renewable energy production [4] is independent of the demand pattern. Accordingly, an increase in price due to high demand can be

This work is supported by the Flemish Ministry of Science (Minister I. Lieten) via the project Linear organized by the Institute for Science and Technology (IWT). J. Tant has a Ph.D. fellowship of the Research Foundation - Flanders (FWO).

B. Dupont, J. Tant and R. Belmans are with the Department of Electrical Engineering (ESAT), Research Group Electrical Energy and Computer Architectures (ELECTA), KU Leuven, Kasteelpark Arenberg 10, 3001 Heverlee, Belgium (e-mail: benjamin.dupont@esat.kuleuven.be), and with Energyville, Dennenstraat 7, 3600 Genk, Belgium. compensated by the availability of renewable energy. If consumers are price responsive, the demand rises with the availability of renewable energy. This demand modification illustrates the transition from a supply follows demand towards a demand follows supply paradigm.

In view of this paradigm shift, residential customer involvement is enhanced by a trend towards automation of appliances [5], [6]. This trend is reflected by pilot projects such as Linear [7], and ADDRESS [8], which use automated smart appliances at the demand side to attain more flexibility in the electricity system. Moreover, industrial interest from the telecom, energy and household appliance sector to automate appliances is growing [9]. To meet this trend, this paper describes a way to model demand response starting from a cost minimizing appliance scheduler in a household under dynamic pricing schemes.

The remainder of this paper is organized as follows. In Section 2 a basic cost reflective dynamic pricing scheme is developed, based on hourly wholesale prices and renewable energy production. Afterwards, Section 3 describes a scheduler for household appliances, which shifts household appliances to the lowest price period using integer linear programming. Based on the attained price and the shifted consumption profile, Section 4 presents a descriptive analysis of the demand modification, distinguishing between week/weekend and autumn-winter/spring-summer days. In addition, this section highlights the convergence of demand with renewable energy production and stipulates the shortterm impact on the electricity costs. In Section 5, the analysis is broadened by assessing the impact of demand response based on two different dynamic pricing schemes. These tariffs account for a higher price impact of RES and a dynamic distribution component. Finally, some general conclusions are derived in Section 5.

\section{BASIC DYNAMIC PRICING SCHEME}

This section describes the development of a basic RTP scheme based on [10]. In this scheme, the day is divided into 24 time blocks of one hour. Each hourly price consists of four price components: energy, transmission, distribution and an additional component compromising levies and taxes. The latter three components remain fixed during the year, while the energy component varies based on hourly day ahead wholesale prices [11]. This wholesale price typically reflects the underlying cost of energy. As more intermittent RES will be integrated taking into account the European 20-20-20 
objectives [12], [13], wholesale price patterns will be affected [4]. Therefore, wholesale prices are adjusted for a $1340 \mathrm{MW}$ and $4320 \mathrm{MW}$ projected capacity level of respectively solar panels and wind turbines in Belgium [14]. Wholesale price adjustment is based on market resiliency analysis. This analysis states the wholesale price sensitivity due to an increase in offer or demand on the market. Based on [11], an hour with $100 \mathrm{MW}$ renewable energy production above average leads to a $€ 0.332$ decrease of the hourly wholesale price. This resiliency factor is applied to annual hourly production profiles of solar and wind plants, derived from publicly available data [15], [16]. Once the adjusted wholesale price is derived, the residential energy price component is attained by multiplying the wholesale price with a rescaling factor. Applying this factor to the wholesale price ensures the principle of revenue neutrality. This states that if an average consumer doesn't change its consumption pattern, the yearly electricity bill for the consumer remains the same when switching to a dynamic pricing scheme.

Once the hourly dynamic energy component is calculated, the three fixed components are added. The results are depicted in Fig. 1. A distinction is made between spring/summer and autumn/winter prices of both week and weekend typical days. For each typical day, the average price pattern is depicted. The figure outlines the variability of price with high prices during the day time and lower prices during the night. Typically weekend prices are lower than week prices and autumn/winter prices are higher than spring/summer prices. In autumn/winter, the price pattern shows a peak towards the evening. In the spring/summer period, the highest prices occur during noon. The flat line represents the baseline price of the RTP scheme. This is the average price a Belgium household pays for consuming $1 \mathrm{kWh}$.

\section{APPLIANCE SCHEDULER}

Starting from the basic dynamic pricing scheme, an appliance scheduler shifts consumption to the lowest price period. Several load control algorithms are discussed in literature [17]-[20]. Most of these studies optimize the appliance schedule for one day, given a theoretical time window in which the predefined power consumption profile can be shifted [18]-[20]. Adding to these studies, this paper applies an appliance scheduler to yearly measured consumption data of residential consumers. These realistic consumption profiles call for a different approach as the power profile and the timing of each appliance cycle differs day by day. Moreover, the scheduler requires the integration of consumer preferences to ensure a more realistic outcome. Therefore, an appliance scheduler based on Integer Linear Programming (ILP) is developed.

\section{A. Data \& Assumptions}

Within the context of the Linear project [7], consumption profiles of sixty Belgian households are measured since 2011. Out of sixty profiles, this paper selected six profiles based on quality and completeness of the data. These six profiles cover a full year on an hourly basis. A general characterization of

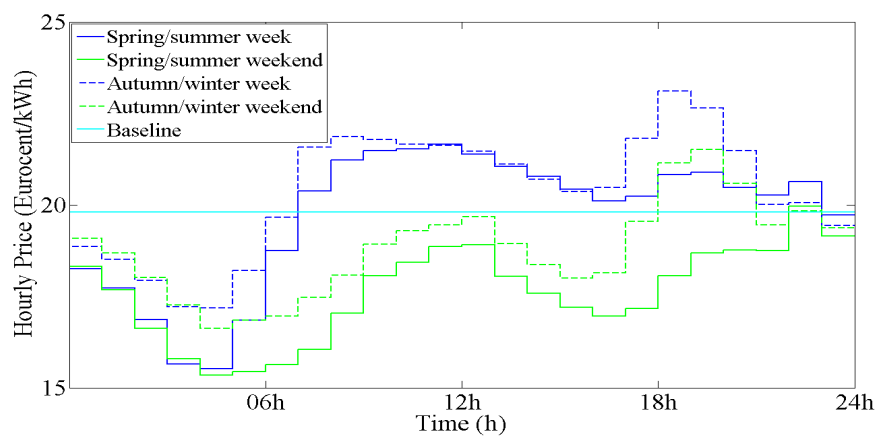

Fig. 1. Average Hourly Price Pattern during spring/summer autumn/winter and week/weekend days.

TABLE I

YEARLY HOUSEHOLD CONSUMPTION

\begin{tabular}{rcccccc} 
Household & 1 & 2 & 3 & 4 & 5 & 6 \\
\hline Total Consumption $(\mathrm{kWh})$ & 7633 & 6616 & 7590 & 7680 & 6121 & 3906 \\
Flex. Consumption $(\mathrm{kWh})$ & 1129 & 270 & 859 & 463 & 1497 & 908 \\
\hline Dishwasher & & $\mathrm{x}$ & $\mathrm{x}$ & & $\mathrm{x}$ & $\mathrm{x}$ \\
Washing Machine & $\mathrm{x}$ & $\mathrm{x}$ & $\mathrm{x}$ & $\mathrm{x}$ & $\mathrm{x}$ & $\mathrm{x}$ \\
Dryer & $\mathrm{x}$ & $\mathrm{x}$ & $\mathrm{x}$ & $\mathrm{x}$ & $\mathrm{x}$ & $\mathrm{x}$ \\
\hline
\end{tabular}

the consumption of these households is given in Table 1. This illustrates that the amount of flexibility originated from white good appliances is limited compared to total consumption. Moreover, flexible consumption depends on the household itself, as the frequency of use and the number of white good appliances varies over the households. While the flexibility accounts for less than $300 \mathrm{kWh}$ in some households, other households have almost $1500 \mathrm{kWh}$ available for flexibility purposes.

Measurements are available on household level and appliance level. The measurements at household level cover total consumption, consisting of both flexible and non-flexible consumption. At appliance level, measurements are available for each of the following white good appliances: washing machine, dryer, and dishwasher. These are considered as flexible, as they can be shifted in time. Two white good consumption profiles are distinguished: the initial measured profile without automation and the optimal profile with automation. The flexibility profile without automation equals the historical profile, while the profile with automation is obtained after running the appliance scheduler. For this model, it is assumed that consumers don't change their behaviour under a dynamic pricing scheme. This implies that a consumer loads and initialises its smart appliance at the same time as in the non-automated case. Afterwards he sets the shifting potential $\left(t_{s p}\right)$ with a timer, stating by when his cycle needs to be finished. Within this period, the appliance cycle is optimally scheduled based upon the dynamic pricing scheme. Only a shift of the full cycle is considered, as the white goods are assumed uninterruptible.

\section{B. Integer Linear Program (ILP)}

1) Objective Function: The objective of the scheduler is to minimize the yearly electricity cost by shifting the smart appliances to the lowest price periods. This is reflected in the following objective function:

$$
\sum_{i j n} C_{i j n} * X_{i j n}
$$


where $C_{i j n}$ reflects the cost for cycle $i$ of appliance $j(1=$ washing machine, $2=$ dryer, $3=$ dishwasher) shifted with $n-1$ hours, where $n \in\left\{1, \ldots, t_{s p}\right\} . X_{i j n}$ represents a binary auxiliary decision variable. If $X_{i j n}=1$, cycle $i$ of appliance $j$ is shifted for $n-1$ hours. The values $C_{i j n}$ are calculated before the ILP is solved. This approach allows to easily add constraints to integrate consumer preferences into the model.

2) Constraints: Cycle $j$ of appliance $i$ needs to be executed once within the shifting interval:

$$
\sum_{n} X_{i j n}=1 \quad \forall i, j .
$$

An appliance cycle needs to be finished before the initial start of the next cycle of the same appliance:

$$
O C F_{i j} \leq I C S_{i+1, j} \quad \forall i, j,
$$

where $O C F_{i j}$ represents the optimal cycle finish for cycle $i$ of appliance $j$ and $I C S_{i+1, j}$ stands for the initial cycle start of cycle $i+1$ of appliance $j$.

The last cycle of the year needs to be finished before the year ends:

$$
O C F_{i j} \leq T_{\text {Max }} \quad \forall i, j,
$$

where $T_{\text {Max }}$ represents the last time interval of the simulation period.

In most cases, there exists a direct link between the cycle of the washing machine and the dryer as the washed load is put in the dryer after finishing. Therefore, the washing machine needs to finish before the dryer cycle is initialised:

$$
O C F_{i 1} \leq I C S_{l 2} \quad \forall i,
$$

where $O C F_{i 1}$ represents the optimal cyle finish of cycle $i$ of the washing machine and $I C S_{l 2}$ stands for the initial cycle start of the linked dryer cycle $l$.

\section{Scheduler Example}

Fig. 2 illustrates the change in consumption pattern after solving the ILP. Initially, the shifting potential $t_{s p}$ is set to 8 hours in this paper. The example depicts the flexible consumption pattern of household 1 for two random weekdays of October. The hourly prices are represented in the top figure. Underneath, the initial and optimal consumption pattern of the different appliances are depicted. For reasons of clarity, the non-flexible consumption is omitted from this figure. Clearly, the smart appliances are shifted towards the lowest cost periods given an $8 \mathrm{~h}$ shifting potential. Moreover, the figure illustrates that the washing machine cycle needs to be finished before the start of the associated dryer cycle.

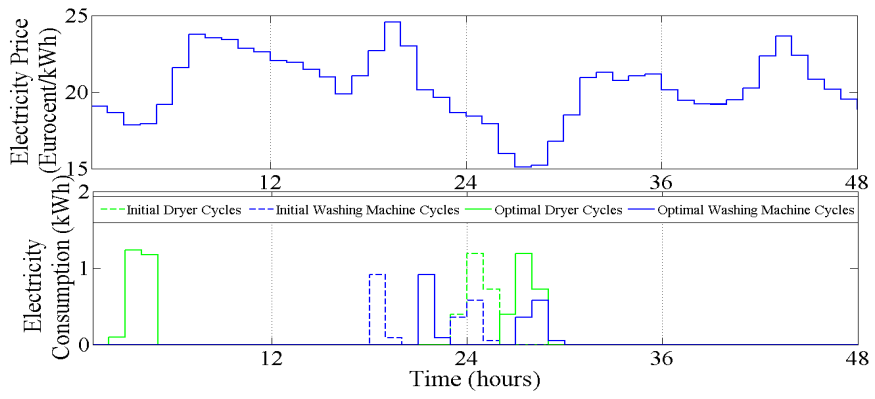

Fig. 2. Hourly price pattern (top), and optimal and initial consumption patterns (bottom) during two random weekdays of October.

\section{Automated DEMAND RESPONSE ANALYSIS}

In this section, the results of using the scheduler for the appliances of the different households are outlined. First, a descriptive analysis shows the general effects of automated demand response on the consumption pattern and the electricity costs. Afterwards, the convergence of flexible consumption with renewable energy production is discussed. Finally, a sensitivity analyses is performed to estimate the impact of the shifting potential.

\section{A. Descriptive Analysis}

To get an overall view on the consumption pattern change due to the use of the appliance scheduler, Fig. 3, Fig. 4, Fig. 5 and Fig. 6 show the initial and shifted consumption patterns for the average household. A distinction is made between four different types of days: week and weekend days of both spring/summer and autumn/winter. The top figures show the average hourly price level for that type of day. The bottom figures reflect the average consumption patterns. Here, a distinction is made between initial and optimal consumption patterns of both total consumption and flexible consumption. The figures show that the amount of flexible consumption is limited compared to total consumption. Although this limitation, shifting the flexible consumption can evoke new peaks in total consumption. Depending on the number of consumers facing dynamic prices, this can lead to new system peaks. Price setting taking into account demand modification can avoid these problems.

The initial flexibility profiles illustrate that in general the quantity of flexibility on weekend days is higher than on week days. Moreover, the initial flexibility availability on week days shows a peak after $22 \mathrm{~h}$. This results from day/night tariff schemes implemented in Belgium. The optimal flexibility profiles show that a large part of consumption is shifted from the late evening to the early morning and from the morning/noon to the late afternoon. This shifting is highly dependent on the dynamic pricing scheme. In spring/summer, the afternoon peak in the optimal flexibility pattern occurs later than in autumn/winter, as prices rise one hour later in spring/summer. In weekends, the night peak in the optimal flexibility pattern occurs later than in weeks, as prices rise one hour later.

Table 2 illustrates the total amount of flexible consumption over all households during the different types of days. Moreover, it depicts the cost reduction if the flexible consumption is shifted towards the lowest price period. The initial cost represents the total costs of the initial flexibility profile, while the optimal cost represents the total costs of the optimal flexibility profile. A total of $5039 \mathrm{kWh}$ is available for flexibility purposes leading to a cost reduction of $€ 74$ or $7.46 \%$ of the initial costs. Highest absolute profits are achieved during the autumn/winter week days. Lowest absolute profits are reached during spring/summer weekend days, eventhough the relative profits compared to the initial costs are highest in this case. Profits during autumn/winter are higher than during spring/summer due to a higher amount of flexibility available, although the effect is small. 


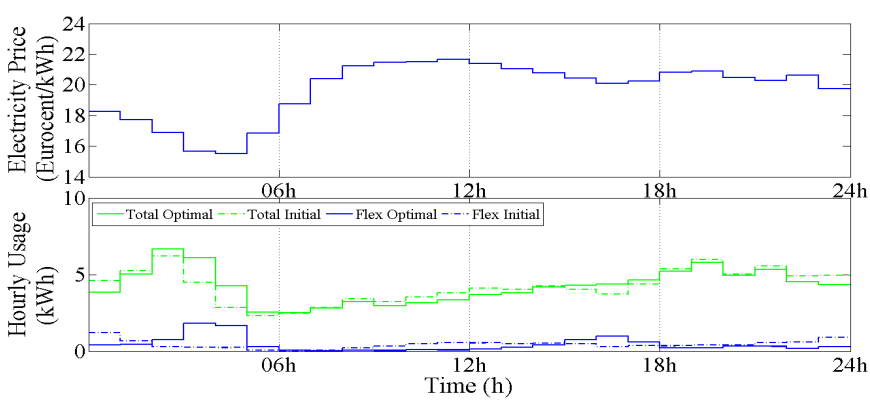

Fig. 3. Average price level (top) and consumption patterns (bottom) during summer/spring week days.

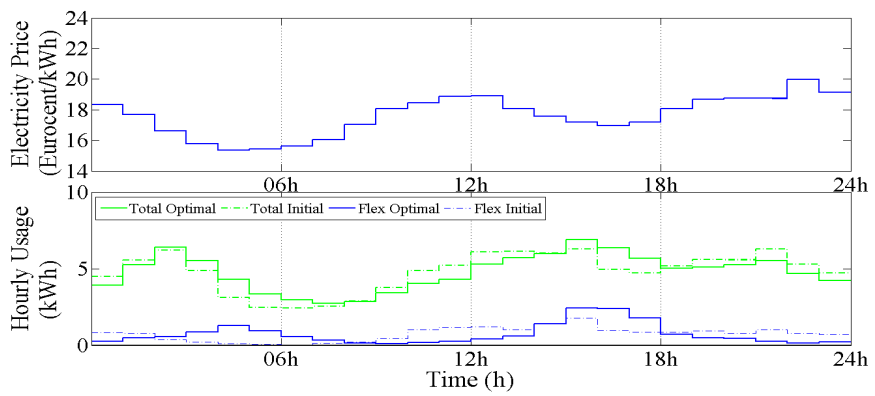

Fig. 4. Average price level (top) and consumption patterns (bottom) during summer/spring weekend days.

In general, total profits are limited due to a limited amount of flexibility and to limited variability in the electricity tariff. Other tariff structures with higher variability can increase total profits. Moreover, individual household benefits show large diversity in total profits ranging from 2.09 to 22.52 euro per household. As a result, the profit picture changes if only households in which the biggest profits can be reaped are targeted.

\section{B. Renewable Energy Uptake}

As the dynamic tariff is affected by RES as discussed in Section 2 and the shifting of consumption is highly dependent on the tariff scheme, more consumption during moments of high renewable energy production is expected. This would illustrate a change from a supply follows demand towards a demand follows supply paradigm. To assess this renewable energy uptake, two different measures are provided: firstly, the correlation between renewable energy production and the optimal and initial flexible demand, and secondly, the amount of consumption during moments with highest renewable energy production.

The correlation measure represents the degree to which renewable energy production and consumption show a tendency to move together. The correlation of renewable energy production and the aggregated initial consumption profile is 0.038 , while the correlation with the aggregated optimal profile is only 0.035 . This implies that the aggregated initial consumption profile shows a small tendency to meet with renewable energy production. If consumption is shifted, this tendency is even smaller, meaning that the optimal flexible consumption aligns less with renewable energy production. This results from the limited impact of renewable energy production on the total electricity tariff. To increase the uptake of renewable energy production, a new tariff design is necessary.

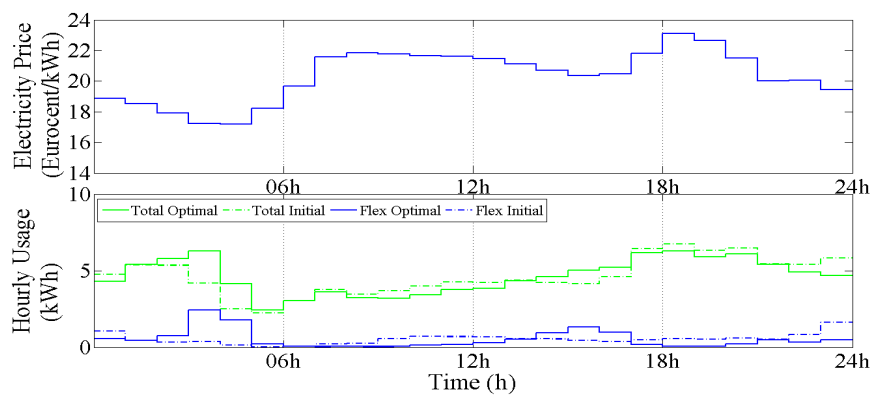

Fig. 5. Average price level (top) and consumption patterns (bottom) during autumn/winter week days.

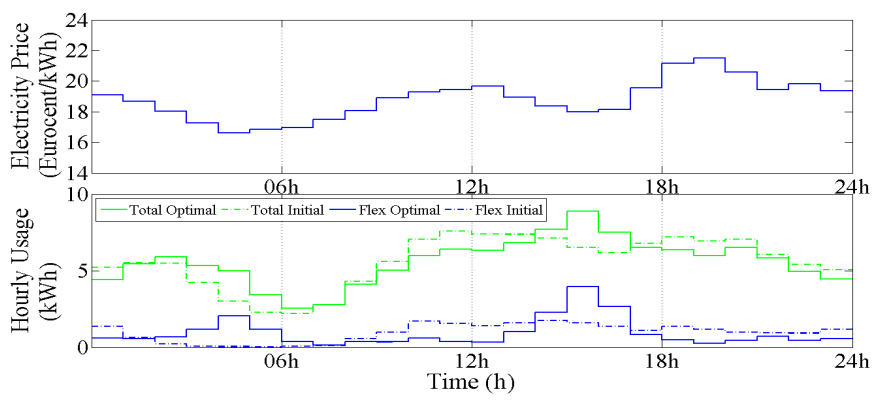

Fig. 6. Average price level (top) and consumption patterns (bottom) during autumn/winter weekend days.

TABLE II

TOTAL FLEXIBLE CONSUMPTION AND COSTS

\begin{tabular}{rcccc}
\hline & $\begin{array}{c}\text { Consumption } \\
(\mathrm{kWh})\end{array}$ & $\begin{array}{c}\text { Initial } \\
\text { costs } \\
(€)\end{array}$ & $\begin{array}{c}\text { Optimal } \\
\text { costs } \\
(€)\end{array}$ & Profits \\
$(€)$ \\
\hline $\begin{array}{r}\text { Spring/summer } \\
\text { week day }\end{array}$ & 1364 & 272 & 252 & $21(7.62 \%)$ \\
$\begin{array}{r}\text { Spring/summer } \\
\text { weekend day }\end{array}$ & 913 & 163 & 148 & $15(9.22 \%)$ \\
$\begin{array}{r}\text { Autumn/winter } \\
\text { week day }\end{array}$ & 1569 & 324 & 301 & $22(6.94 \%)$ \\
$\begin{array}{r}\text { Autumn/winter } \\
\text { weekend day }\end{array}$ & 1193 & 230 & 214 & $16(6.75 \%)$ \\
\hline Total & 5039 & 988 & 915 & $74(7.46 \%)$ \\
\hline
\end{tabular}

As moments of highest renewable energy production are the most critical for the electricity system, the amount of consumption during these moments is measured. Therefore, hours are ranked from low to high renewable energy production and divided in 5 intervals. For each interval, the amount of initial and optimal flexible consumption is specified. In the interval with the highest level of renewable energy production, $21.6 \%$ and $22.3 \%$ of initial and optimal flexible consumption respectively is assigned. This again illustrates the limited positive correlation between renewable energy production and flexible consumption. In order to increase the uptake of renewable energy, a different tariff design is advisable.

\section{Shifting Potential}

The impact of shifting flexible consumption remains limited with a shifting potential of 8 hours. Therefore, a sensitivity analyses is performed on the shifting potential. Table 3 depicts the impact of varying the shifting potential on total profits. When the shifting potential equals 2 hours, profits diminish to almost $€ 0$. As the duration of most appliance cycles lays 
within a 1 and $2 \mathrm{~h}$ interval, demand modification is limited. When the shifting potential rises, profits increase. This increase lowers when reaching a higher level of shifting potential. This is attributable to the fact that biggest benefits are already harvested under lower shifting potential and that the larger the shifting potential becomes, the more the appliance cycle shifting is restricted by other appliance cycles. Total relative shifting profits rise to almost $10 \%$ compared to the initial flexibility costs in the case of a $12 \mathrm{~h}$ shifting potential. If the cost of non-flexible consumption is added, this number decreases to $1.23 \%$. These figures illustrate that even in the case of high shifting potential, profits remain limited under the current dynamic tariff structure.

\section{OTHER DYNAMIC TARIFF STRUCTURES}

To overcome the limited impact of demand response on profits and renewable energy uptake due to the limited amount of flexibility from white goods, other dynamic tariff structures are constructed. In what follows, the limited profits are accounted for by bringing more variability in the tariff structure, while the renewable energy uptake is obtained by enlarging the price impact of RES.

\section{A. Renewable Tariff}

This tariff structure increases the impact of renewable energy production on wholesale prices to allow a higher renewable energy uptake. Therefore, a higher resiliency is assumed by multiplying the resiliency of the basic dynamic pricing scheme of Section 2 with a factor. As the influence of renewable energy production on future prices is difficult to predict, this approach is acceptable. A basic renewable tariff is attained by multiplying the resiliency with 5 , while an extreme renewable tariff is developed by multiplying with 10 . This results in a resiliency factor of $€ 1.66$ and $€ 3.32$ per $100 \mathrm{MWh}$ respectively. After adapting the basic and extreme renewable tariff, the tariffs are rescaled to take into account the principle of cost neutrality. In the basic renewable tariff scheme, the energy tariff component becomes negative during few hours a year. The total tariff remains positive, as the negative energy component is compensated by the other tariff components. When applying the extreme renewable tariff, the total tariff becomes negative during few hours a year, implying that a consumer is remunerated for consuming electricity during moments with high renewable energy production.

Columns one to three of Table 4 illustrate the impact of the basic and extreme renewable tariff scheme on the correlation between renewable energy production and flexible consumption. The correlation increases from 0.035 for the basic dynamic tariff to 0.077 and 0.103 for the basic and extreme renewable tariff respectively. This implies that a higher impact of renewable energy production on the dynamic pricing scheme, leads to higher flexible demand during moments of high renewable energy production. This tendency is also reflected in Fig. 7. This figure ranks the renewable energy production time steps from low to high production and divides it in 10 intervals in which each interval represents $10 \%$ of time. For each interval, the amount of consumption is specified for both the initial flexible consumption as for optimal flexible consumption based on the basic dynamic and the renewable tariff schemes. It can be seen that during moments of high renewable energy production, consumption is higher if the impact of renewable energy production on the tariff is higher. Although this trend is deduced from both correlation and interval measurements, the amount of consumption shifted to moments with high renewable energy production still remains limited. This results from the fact that the impact of renewable energy production is mainly attributable to the availability of wind energy. As the variability of the selected wind power profile is higher on a daily than on an hourly basis, the shifting potential of white goods is not sufficient to bridge this period.

Next to the correlation impact, columns one to three of Table 4 also show the impact of renewable tariffs on the costs of the different tariff components. As the distribution tariff is fixed over the year, costs for this component remain the same. If the energy component is considered, the costs of both initial and flexible tariff components go down if the impact of renewable energy production on the tariff increases. As more variability is integrated in the tariff, more profits can be attained from shifting.

TABLE III

PROFIT IMPACT OF SHIFTING POTENTIAL

\begin{tabular}{rcccccc}
\hline & $2 \mathrm{~h}$ & $4 \mathrm{~h}$ & $6 \mathrm{~h}$ & $8 \mathrm{~h}$ & $10 \mathrm{~h}$ & $12 \mathrm{~h}$ \\
\hline Profits (€) & 0.7 & 24.4 & 54.7 & 73.8 & 87.4 & 96.7 \\
$\begin{array}{r}\text { Profits to initial flexibility } \\
\text { payment (\%) }\end{array}$ & 0.0 & 2.5 & 5.5 & 7.5 & 8.8 & 9.8 \\
$\begin{array}{r}\text { Profits to initial total } \\
\text { payment (\%) }\end{array}$ & 0.0 & 0.3 & 0.7 & 0.9 & 1.1 & 1.2 \\
\hline
\end{tabular}

TABLE IV

CORRELATION AND COST IMPACT OF DIFFERENT TARIFF STRUCTURES

\begin{tabular}{rcccccc}
\hline & $\begin{array}{c}\text { Basic } \\
\text { dynamic } \\
\text { tariff }\end{array}$ & $\begin{array}{c}\text { Renewable } \\
\text { tariff }\end{array}$ & $\begin{array}{c}\text { Distr. } \\
\text { tariff }\end{array}$ & $\begin{array}{c}\text { Renewable } \\
\text { distr. tariff }\end{array}$ \\
$\begin{array}{r}\text { Resiliency } \\
\text { multiplication }\end{array}$ & 1 & 5 & 10 & 1 & 5 & 10 \\
\hline Ini. Correlation $(-)$ & 0.038 & 0.038 & 0.038 & 0.038 & 0.038 & 0.038 \\
Opt. correlation $(-)$ & 0.035 & 0.077 & 0.103 & 0.030 & 0.052 & 0.074 \\
\hline Ini. distr. cost $(€)$ & 445 & 445 & 445 & 461 & 461 & 461 \\
Opt. distr. cost $(€)$ & 445 & 445 & 445 & 375 & 377 & 381 \\
Ini. energy cost $(€)$ & 385 & 382 & 379 & 385 & 382 & 379 \\
Opt. energy cost $(€)$ & 311 & 303 & 284 & 314 & 307 & 290 \\
\hline Distr. profits $(€)$ & 0 & 0 & 0 & 85 & 84 & 80 \\
Energy profits $(€)$ & 74 & 80 & 95 & 71 & 76 & 89 \\
Total profits $(€)$ & 74 & 80 & 95 & 157 & 160 & 169 \\
\hline
\end{tabular}

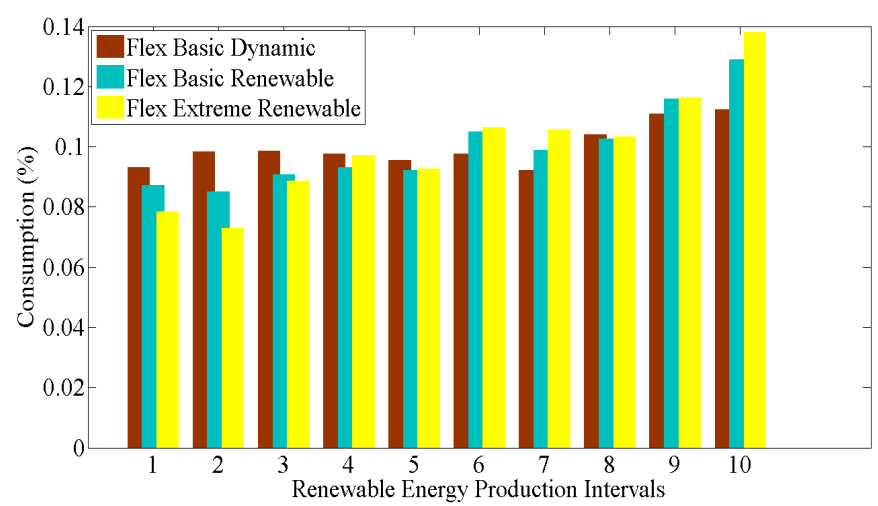

Fig. 7. Flexible consumption convergence with renewable energy production. 


\section{B. Distribution Tariff}

This tariff structure builds further on the basic dynamic tariff structure from Section 2, by adding a dynamic distribution component to the tariff. Based on the average distribution tariff component and average load profiles [21], an hourly dynamic distribution component is attained. In this tariff structure, prices are high during peak moments as these moments typically contribute to increased ageing of distribution feeders and transformers [22].

Column 4 of Table 4 depicts that adding this dynamic distribution component reduces the correlation between renewable energy production and optimal flexible consumption slightly. Profits are also affected, as distribution costs can be reduced considerably. Compared to the basic dynamic tariff scheme, also the energy costs are affected although this effect is insignificant. This implies that adding variability in the distribution component can reduce distribution costs considerable, while preserving the energy savings. Adding up both energy and distribution profits, leads to more than double of the profits compared to the basic dynamic tariff.

\section{Renewable Distribution Tariff}

By combining the dynamic distribution component from the distribution tariff with the dynamic energy components from the renewable tariffs, the renewable distribution tariffs are attained. Results of these tariff structures are visualised in columns five and six of Table 4 . As the highest variability can be found in these tariffs, profits are highest. In the extreme renewable distribution tariff, profits rise to $€ 169$. This large profit due to the inclusion of a dynamic distribution component, comes at the expense of the renewable energy uptake.

\section{CONCLUSIONS AND CONTRIBUTIONS}

\section{A. Conclusions}

This paper develops a scheduler for white good appliances. Based on a hourly electricity consumption measurements of households and on dynamic pricing structures, white goods are shifted to the lowest cost period taking into account customer preferences.

In general, the flexibility potential of white good appliances is limited. This picture can change when looking at individual households. The flexibility potential depends on the amount, the shifting potential and the timing of flexibility. For all considered households, the amount of flexible consumption is limited to $15 \%$ of total consumption. The shifting potential is restricted by the customer preferences and the linkage between the different cycles of white good appliances. For the timing of flexibility, a distinction should be made between the timing over the year and during the day. For the considered households, more flexibility from white goods is available on an average weekend day than on an average week day. Over the different seasons, most flexibility is available in the morning/noon and in the evening.

Starting from the available flexibility, consumption is shifted to the lowest cost period based on a basic dynamic tariff scheme. As prices are lowest during the early morning and the late afternoon, consumption is shifted to these moments. As flexibility is limited over the different households, profits from shifting remain limited and renewable uptake is not affected considerably. To amplify these results, new tariff structures need to constructed, which add more variability and an higher impact of renewable energy production to the tariff structure.

Renewable energy tariff schemes can promote consumption during moments of high renewable energy production by lowering tariff during these moments. Although more consumption is shifted to moments with high renewable energy production, results remain limited. This is attributable to limited flexibility of white goods and to limited variability of wind power over the time interval of the shifting potential. To increase the profits by shifting, more variability needs to be included in the tariff structure. Making the distribution component dynamic, significantly contributes to this.

To broaden the understanding of demand response, other innovative tariff structures should be tested. Moreover, other flexible resources like electric vehicles and electric heating are characterised by a different flexibility potential. Taking into account these resources, can contribute to the analysis.

While the modeling of residential demand response and the development of dynamic pricing structures remains theoretical in this paper, results lead to new insights in the short-term impact of automated demand response under dynamic pricing structures. To add to the realisticity, the Linear pilot project is currently testing this set-up on more than 100 households in Flanders [7]. Based upon the results of this pilot, more general results can be derived.

\section{REFERENCES}

[1] European Commission, "A Roadmap for Moving to a Competitive Low Carbon Economy in 2050," SEC (2011) 112, Brussels, March 2011.

[2] European Climate Foundation, "Roadmap 2050, a Practical Guide to a Prosperous, Low-carbon Europe," April, 2010.

[3] M.C. Caramanis, R.E. Bohn, and F.C. Schweppe, "Optimal Spot Pricing: Practice and Theory," IEEE Transactions on Power Apparatus and Systems, Vol. PAS-101, Issue 9, Pp. 3234-3245, 1982.

[4] T. Jónsson, P. Pinson and H. Madsen, "On the Market Impact of Wind Energy Forecasts," Energy Economics, Vol.32, pp.313-320, 2010

[5] A. Faruqui, R. Hledik, and S. Sergici, "Piloting the Smart Grid," The Electricity Journal, Vol. 22, Issue 7, Aug./Sept., 2009.

[6] D. Cooke, "Empowering Customer Choice in Electricity Markets," Information Paper, International Energy Agency, Oct., 2011.

[7] B. Dupont, P. Vingerhoets, P. Tant, K. Vanthournout, W. Cardinaels, T. De Rybel, E. Peeters, and R. Belmans, "LINEAR Breakthrough Project: Large-Scale Implementation of Smart Grid Technologies in Distribution Grids," IEEE PES International Conference and Exhibition on Innovative Smart Grid Technologies (ISGT Europe), Berlin, Germany, October 14-17, 2012.

[8] R. Belhomme, R. Cerero, G. Valtorta, A. Paice, F. Bouffard, R. Rooth, and A. Losi, "ADDRESS - Active Demand for the Smart Grids of the Future," International Conference and Exhibition on Electricity Distribution, Prague, June, 2009.

[9] J. M. Horwitz, B. Kallo, and R. Fong, "Clean Technology, 2010: A Smart Grid Odyssey,” Baird, Energy Research, Jan., 2010.

[10] B. Dupont, C. De Jonghe, K. Kessels, and R. Belmans, "Short-term Consumer Benefits of Dynamic Pricing," IEEE, International Conference on the European Energy Market, $8^{\text {th }}$ edition, Zagreb, Croatia, May, 2011.

[11] The Belgian Power Exchange (BELPEX). [Online]. Available: http://www.belpex.be 
[12] European Council, "Climate-energy legislative package," 2009.

[13] European Parliament, "Resolution on the action plan for energy efficiency," 2008.

[14] Federal-Regional Energy Consultation Group, "National Renewable Energy Action Plan pursuant to Directive 2009/28/ec," Belgium, Nov., 2010.

[15] Soda, Solar Energy Data for Professionals. [Online]. Available: http://www.soda-is.com/eng/index.html

[16] KNMI, Royal Dutch Meteorological Institute, "Potential Wind Speeds of the Netherlands". [Online]. Available: http://www.knmi.be, last consulted in October 2010

[17] A.-H. Mohsenian-Rad, A. Leon-Garcia, "Optimal Residential Load Control With Price Prediction in Real-Time Electricity Pricing Environments," IEEE Transactions on Smart Grid, Vol.1, Issue 2, pp. 120-133, Sept., 2010.

[18] K. C. Sou, J. Weimer, H. Sandberg, and K. H. Johansson, "Scheduling Smart Home Appliances Using Mixed Integer Linear Programming," IEEE Conference on Decision and Control and European Control Conference, pp. 5144 - 5149, Dec., 2011 .

[19] C. Roe, S. Meliopoulos, R. Entriken, S. Chhaya, "Simulated Demand Response of a Residential Energy Management System," IEEE Energytech Conference, Cleveland, USA, May, 2011.

[20] P. Du, N. Lu, "Appliance Commitment for Household Load Scheduling," IEEE Transactions on Smart Grid, Vol.2, Issue 2, pp. 411-419, June, 2011.

[21] Belgian federation of system operators for electricity and gas (SYNERGRID). [Online]. Available: http://www.synergrid .be

[22] K. Najdenkoski, G. Rafajlovski, and V. Dimcev, "Thermal aging of distribution transformers according to IEEE and IEC standards," in IEEE Power Engineering Society General Meeting, 2007, pp. 1-5.

\section{BIOGRAPHIES}

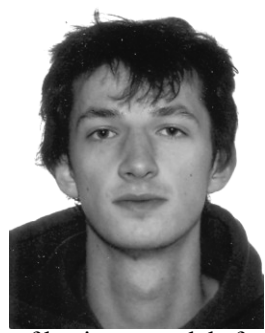

Benjamin Dupont (S'10) was born in Belgium on September 2, 1986. He received his master degree in commercial engineering in 2009 at the Faculty of Business and Economics of the KU Leuven, Belgium. Since 2009, he is working as a Research Assistant towards a Ph.D. in the research group ELECTA, department of Electrical Engineering of the KU Leuven. His research interests include the implementation of demand response programs and its effect on the power system, and the development of business models for Smart Grids.

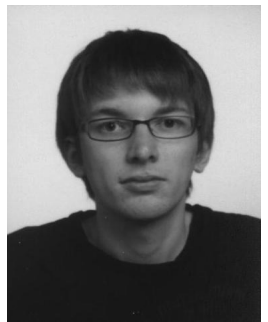

distribution grids.

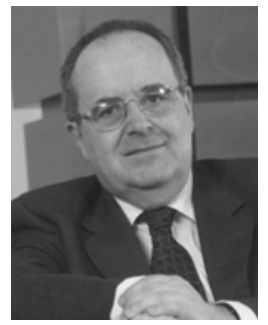

Ronnie Belmans (S'77-M'84-SM'89-F'05) received the M.S. degree in electrical engineering in 1979 and the Ph.D. degree in 1984, both from the KU Leuven, Belgium, the Special Doctorate in 1989 and the Habilitierung in 1993, both from the RWTH, Aachen, Germany. Currently, he is a full professor with the KU Leuven, teaching electric power and energy systems. His research interests include techno-economic aspects of power systems, power quality and distributed generation. He is also guest professor at Imperial College of Science, Medicine and Technology, London-UK.

Jeroen Tant (S'08) received the M.Sc. degree in Electrical Engineering from the University College Howest, Kortrijk, Belgium, in 2007 and the M.Sc. degree in Mathematical Engineering from the KU Leuven, Leuven, Belgium, in 2009. He is currently working towards the Ph.D. degree at the KU Research Foundation Flanders (FWO). His research topics include the simulation, modeling, and optimization of power electronic systems and power Lond 